\title{
A 5 Year Retrospective Analysis of Self Discharge from the Medical Wards of a Nigerian Tertiary Hospital
}

\author{
Ojobi JE ${ }^{1}$, Ugwu E ${ }^{2}$, Idoko $\mathrm{PO}^{3}$, Ogiator $\mathrm{MO}^{4}$, Gomerep \\ $\mathbf{S S}^{5}$, Orkuma JA'. \\ ${ }^{1,3}$ Department of Medicine, Federal Medical Centre, PMB \\ 1020204, Makurdi, Benue state, ${ }^{2}$ Enugu State University of \\ Science and Technology, Enugu and ${ }^{5}$ Jos University Teaching \\ Hospital, Jos, Plateau State. \\ ${ }^{4}$ Department of Medicine and ${ }^{6}$ Department of Haematology, \\ Benue State University Teaching Hospital, Makurdi, Benue \\ State.
}

\author{
*Correspondence \\ Dr.Ojobi J.Echobu : ojobijoe@yahoo.com
}

\begin{tabular}{|l|l|}
\hline $\begin{array}{l}\text { Article } \\
\text { information }\end{array}$ & $\begin{array}{l}\text { Date Submitted: 2/4/2020. } \\
\text { Date Accepted: } 8 / 6 / 2020 \\
\text { Date Published: June, 2020 }\end{array}$ \\
\hline
\end{tabular}

d.

https://doi.org/10.46912/jbrcp.152

\begin{abstract}
Self-discharge (SD) of hospitalized patients is an adverse clinical event often resulting from a fundamental disagreement between the patient or an interested third party and the attending physician and / or the hospital environment. This culminates in the patient's withdrawal of their initial voluntary consent for hospitalisation and abrupt termination of in patient medical care. Patients who left hospital admission against the advice of their doctors are both a concern and a challenge for individuals in the health industry. it has negative impact on treatment outcomes and exposes the clinician and health care administrators to the hazards of litigations. This study was aimed at determining the incidence of SD and associated factors in medical admissions. A hospital based retrospective study of patients who self discharged from medical wards of Federal Medical Center, Makurdi from June 2012 - May 2017. Approval was obtained from the institution's research ethics board. Thirty one individuals (0.62\% of total admission) self discharged within the study period. Financial constraints was responsible for 32.2\% (10) of SD followed by proximity to social support 19.4\% (6). Five patients $(16.1 \%)$ elected not to disclose any reasons. The incidence reduced from $0.21 \%$ to $0.02 \%$ at the start and end of study period respectively. Though SD was relatively low in this study, the incidence could be reduced further by expanding the scope of health insurance scheme, skilful communication and negotiating patient management using patient-centredmethods.
\end{abstract}

Keywords: Self-discharged, Consent withdrawal, Patient-centred approach

\section{INTRODUCTION}

$\mathrm{P}$ atients discharge themselves from hospital when they opt to leave admission against the advice of the managing team of healthcare workers. Self discharge of hospitalized patients is an adverse clinical event often resulting from a fundamental disagreement between the patient or an interested third party and the attending 
physician and/or the hospital environment. ${ }^{1}$ This culminates in the patient's withdrawal of their initial voluntary consent for hospitalisation and abrupt termination of in-patient medical care. ${ }^{1,2}$ Patients who self discharge are both a concern and a challenge for individuals in the health industry ${ }^{2}$ as it negatively impacts treatment outcomes, healthcare resource utilization and exposes the clinician and health care administrators to the hazards of litigations. ${ }^{3,4,5,6}$

$\mathrm{SD}$ is a universal problem, plaguing both rural and urban hospitals. However, interest in this area has generally focused on large urban hospitals and on specific patients groups, such as psychiatric patients. ${ }^{7}$ Worldwide, the reported self discharge prevalence rate for general medical admissions ranges from $0.7 \%$ to $2.8 \%$, being higher in developing than developed countries. ${ }^{1,7,8}$

Report of SD incidence is widely variable, being more than $20 \%$ in large urban hospitals, especially among alcoholics, drug abusers and psychiatric patients, to less than $4 \%$ for medical admission and even lower than $1 \%$ in small rural hospitals and medical wards. ${ }^{9,10}$ Previous multi - centre studies from the United States of America have found an association between younger age, male gender, black race, presence of psychiatric disorders, substance abuse disorders, emergent admission, previous hospitalization and lack of health insurance and SD., ${ }^{8,10}$ Hospital characteristics associated with SD include urban location, private ownership and high or low Herfindahl index scores. ${ }^{10}$

In less developed parts of the world, procedural pitfalls are rife when clients leave against the advice of managing physicians. ${ }^{11}$

This study highlighted the need for better understanding of the factors associated with this challenge as witnessed in medical wards all over the world. These factors are important in formulating a clear and uniform guideline in dealing with SD as well as improvement of the responsiveness of existing service channels.

\section{MATERIALS AND METHODS}

\section{Study area}

The review was carried out at Federal Medical Centre (FMC), Makurdi, Benue State. FMC, Makurdi is a rapidly expanding tertiary centre currently consisting of 400 bed spread over different complexes such as the mission ward, psychiatric complex, Dento-maxillary complex, the federal staff clinic, the national health insurance Clinics at the riverside / Hospices and palliative care and the permanent site about $15 \mathrm{~km}$ from these sites. FMC has 3 satellite facilitiess in each of the 3 senatorial zones offering full hospital services.

Benue state is in the North central region of Nigeria on geographical coordinates of latitude $7^{\circ} 42^{\prime}$ and $10^{\circ} 0^{\prime}$ East, longitude $6^{\circ} 25^{\prime}$ and $6^{\circ} 8^{\prime}$ North. Makurdi, the capital of Benue state is located along the banks of River Benue. It is a metropolitan city with several federal and state institutions including a Federal University, a state University and other government and private tertiary institutions.

Benue share boundary with 5 other states within Nigeria; Nasarawa to the North, Taraba to the East, Cross River to the South, Enugu to the South West and Kogi to the West. The state share a common boundary with the republic of Cameroun on her South Eastern front. The 2006 National Census puts the state population at 4,210,244 made of 2,164,058 males and 2,055,186 females.

\section{Research Design}

A hospital-based retrospective study of patients who discharged themselves from the medical wards of Federal Medical Centre, Makurdi from June 2012 - May 2017 (5 years) by extraction of relevant records of eligible patients during the period under review. Overall, 4,966 admission cases were reviewed. Ethical approval was obtained from the institution's ethics committee in April, 2012. Both male and female medical wards maintained an admissions / discharge summary for each patient that was admitted. The number of self discharged patients was obtained from this summary and the corresponding file extracted from the hospital Records Department. Records of patients were considered appropriate for inclusion in the study if they had left admission against the advice of the healthcare team within the stipulated time. Patients who self discharged at the emergency room were excluded.

\section{Statistical Analyses}

The data generated was analyzed using Statistical Package for Social Sciences (SPSS, IBM version 23.0; SPSS Inc., Chicago, IL, USA). Frequencies and percentages were computed for categorical variables while continuous variables were presented as mean and standard deviation. 


\section{RESULTS}

Thirty one individuals out of the total 4,966 cases admitted within the reviewed period $4,966(0.62 \%$ of total number of admissions into the medical wards) left the wards against their physicians consent within the five years reviewed. This number was made up of seventeen males and seven females with a male:female ratio 2.4:1. They were between the ages of $20-81$ years with a mean age of 50.9 years. Individuals in the fifth decade self discharged the most while the younger and older decades had the least prevalences. Other aspects of age and gender in relation to self discharge are presented in Figure I.

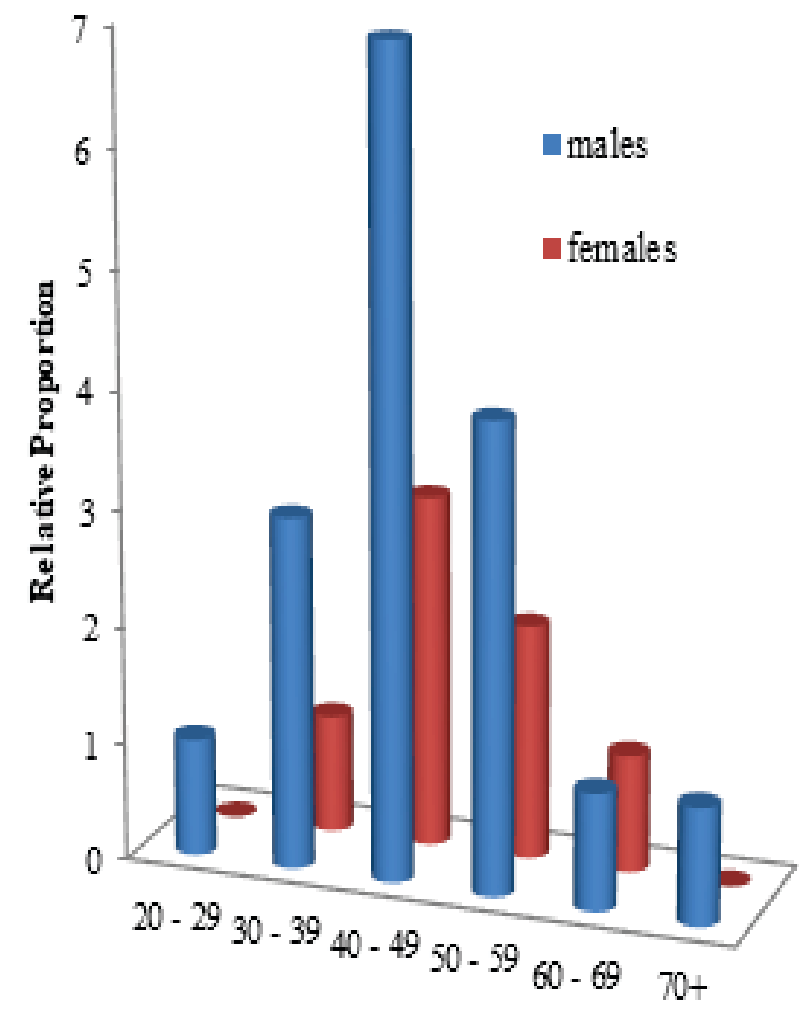

Age range

Figure 1: Age and sex distribution of patients who self - discharged from hospital against medical advice (June 2012 - May 2017).

\section{Reasons for self discharge}

Most persons that self discharged did so because of financial constraints $(32.3 \%)$. By order of magnitude, this was followed by proximity to social support (19.4\%), which is usually a family member(s). In a sizeable proportion of individuals that SD, no reasons were specified in their clinical case notes. The reasons are depicted in table I.

\section{Temporal Pattern}

The incidence of SD reduced progressively from $0.21 \%$ to $0.02 \%$ from the start to the end of the study period respectively as depicted in Figure II.

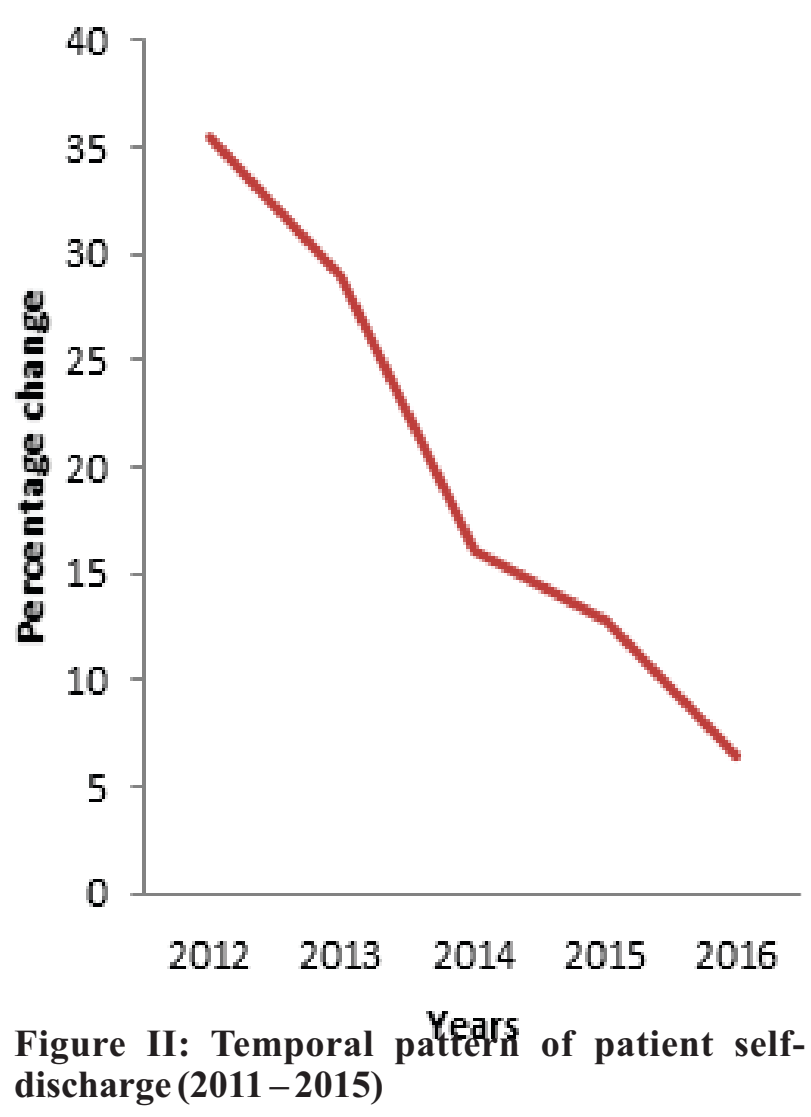


Table 1: Indications/Reasons for Self-discharge

\begin{tabular}{lllllll}
\hline $\begin{array}{l}\text { Year / } \\
\text { Indications }\end{array}$ & $\begin{array}{l}\mathbf{2 0 1 2} \\
\mathbf{n}(\%)\end{array}$ & $\begin{array}{l}\mathbf{2 0 1 3} \\
\mathbf{n}(\%)\end{array}$ & $\begin{array}{l}\mathbf{2 0 1 4} \\
\mathbf{n}(\%)\end{array}$ & $\begin{array}{l}\mathbf{2 0 1 5} \\
\mathbf{n}(\%)\end{array}$ & $\begin{array}{l}\mathbf{2 0 1 6} \\
\mathbf{n}(\%)\end{array}$ & $\begin{array}{l}\text { Total } \\
\text { n (\%) }\end{array}$ \\
\hline Financial constraints & $3(16.7)$ & $3(16.7)$ & $2(12.5)$ & $1(8.3)$ & $1(4.2)$ & $10(32.2)$ \\
Proximity to (social) support & $2(7.7)$ & $1(3.8)$ & $1(3.8)$ & $1(3.8)$ & $1(3.8)$ & $6(19.4)$ \\
Prefer Alternative treatment & $1(3.8)$ & $0(0)$ & $1(3.8)$ & $0(0)$ & $1(3.8)$ & $5(16.1)$ \\
Undisclosed & $1(3.8)$ & $1(3.8)$ & $1(4.2)$ & $0(0)$ & $0(0)$ & $5(16.1)$ \\
Perception of improved wellbeing & $1(3.8)$ & $1(3.8)$ & $0(0)$ & $0(0)$ & $0(0)$ & $3(9.7)$ \\
Disagreement on treatment modality & $0(0)$ & $1(3.8)$ & $1(4.2)$ & $0(0)$ & $0(0)$ & $2(6.5)$ \\
\hline Total & $\mathbf{1 1 ( 3 5 . 5 )}$ & $\mathbf{9 ( 2 9 . 0 )}$ & $\mathbf{5 ( 1 6 . 1 )}$ & $\mathbf{4 ( 1 2 . 9 )}$ & $\mathbf{2 ( 6 . 5 )}$ & $\mathbf{3 1 ( 1 0 0 )}$ \\
\hline
\end{tabular}

\section{DISCUSSION}

In this study, financial constraints was the prime reason for individuals that left admissions against the managing team's advice. A study that was in agreement with this one reaffirming the place of money and or resources as a preeminent factor in SD was from south - west Nigeria by Ahmed et al. ${ }^{12}$ It was a study that encompassed all the departments in the hospital, unlike this work which focused only on the medical wards. Financial constraint remain a major reason in other studies ${ }^{13,14,15,16}$ where direct comparison was made difficult because of patient selection ${ }^{14,15}$ and the type of study. ${ }^{16}$

In many parts of the world, procedural pitfalls are rife when clients leave against the advice of managing physicians. ${ }^{10}$ This, in turn, exposes practitioners and institutions to ethico - legal issues. Many health centres including the hospital where this study was carried out has neither a SD release form nor any clinical guideline for clinicians faced with requests for $\mathrm{SD}^{2,10}$ Typically, in these centres, a space is merely created in the patients' clinical case notes for the patient or their relatives or other interested third party to write out the request and append their details including signature. Similar to Nwokediuko and Arodiwe's observation, ${ }^{10}$ no follow-up arrangement was made for any of the patients that self discharged in this study. They therefore concluded that the procedure adopted by medical staff in dealing with this very sensitive medical issue with high potential for serious ethical and legal breaches needs radical reforms. ${ }^{10}$ indeed, such reforms may start from the very beginning of it all; an agreement on nomenclature. Not only do different regions of the world refers to this phenomenon by different names, it is also a fact that different institutions even in the same locality refer to this event with different appellations. It is therefore an occurrence with many synonyms such as Against Medical Advice - AMA, Discharge Against Medical Advice - DAMA, Discharge At Own Risk DAOR, Signed Against Medical Advice - SAMA, Left Against Medical Advice - LAMA, Self Discharged Against Medical Advice-SDAMA, etc.

In this study, $16.1 \%$ of individuals that self discharged over the five year period that this study analysed did not specify any reason(s) for their action. This was a far cry from the observation by Ding et $\mathrm{al}^{11}$ to the effect that $85.2 \%$ of the patients that self discharged did not state a reason. However, their patients were selected from the emergency unit. Emergent admissions pose special challenges, ${ }^{12}$ one of which is undisclosed reason(s) for leaving against the wish of attending medical personnel. Nwokediuko et al also observed a very high rate of SD which they blamed on the absence of a standing protocol to deal with this phenomenon. ${ }^{10}$

A patient's choice of an alternate care path should be documented in the medical records. ${ }^{17,18}$ Contrary to the belief of many health care professionals, this does not require the patient's signature. ${ }^{17} \mathrm{Up}$ to $16.1 \%$ of the records this study utilized choose to leave hospital admissions for alternative treatment modality. Other researchers observed a preference for alternative therapy of $17.7 \%$ in a hospital - wide study with a predominant paediatric group 
over the three years the researchers evaluated ${ }^{16}$ and $23.1 \%$ in a rural setting in south west Nigeria in another three year survey. ${ }^{19}$

Often times, the managing team does not understand the extent of its liabilities. ${ }^{5,17,18,20}$ Devitt et $\mathrm{al}^{6}$ described four cases of malpractice litigation following SD, and concluded that while the fact of SD may provide some protection, it does not grant full immunity from the law. In fact, it is not possible to have a document that absolves the healthcare team from responsibility for adverse events. ${ }^{17}$ The concept of labelling a patient as having self discharged may need further consideration. This label may create an antagonistic relationship between the patient and the medical team that limits ongoing care. It also seems to contradict the accepted model of shared decision-making. ${ }^{17}$ In 'shared decision-making' the physician provides the patient with information regarding treatment options that are tailored to a patient's circumstances and values. A patient-centered care model dictates that regardless of the care path chosen by a competent patient, appropriate discharge prescriptions and follow up plans should be ensured. ${ }^{20}$ When a patient leaves hospital under circumstances that do not seem ideal, the focus should be on establishing the patient's capacity and arranging the safest plan for follow up, rather than creating conflict. Knowledge that a patient was interested in medical treatments but could not afford high costs may enable the physician to propose a cheaper alternative rather than no treatment at all. ${ }^{17}$

Other researchers in this field have clearly stated that the need to properly assess, counsel and educate the patient and their relatives cannot be over - emphasized. Patients and / or family members should also be made aware of the possibility of re-admission if and when they change their minds or the symptoms worsen. The physician should ensure that all these steps are properly documented in the patient records and that the authentic signature of the patient or the designated surrogate decision maker is appended on the discharge form in the presence of a witness. ${ }^{20}$ They also proposed a SD form similar to the informed consent document (though much simpler) where the patient's understanding of the disease condition, the possible consequences of premature discharge and their reasons for SD would be highlighted. This form should also be translated into the patient's own language for better comprehension. In cases where physicians are not completely convinced that the patient fully comprehends the situation, or that the surrogate decision makers are protecting the patient's best interests, they can approach the courts for permission for involuntary or compulsory hospitalisation. ${ }^{20}$

Skilful communication, flexible routines / policies and procedures, negotiable management options, good clinical care and thorough documentation constitute the cornerstones of dealing with this problem. ${ }^{2}$ the study was limited by the fact that it was carried out in only one department of the institution. It follows therefore that generalisation of findings may not be appropriate as other factors may be pre-eminent in other departments. Also, the patients that self discharged could not be followed up to know the outcome of their action.

\section{CONCLUSION}

The prevalence of self discharge was relatively low in this study. Financial limitation was the prime factor responsible for majority of cases. Although the incidence reduced progressively, some of the suggestions outlined above would need to be implemented along with other sustainable modalities to reduce this clinical menace to a minimum.

\section{REFERENCES}

1. Alebiosu CO, Raimi TH. A study of hospital patients' discharge against medical advice in the Ogun State University Teaching Hospital, Sagamu, Nigeria. Nig Med Pract. 2001; 40: 33 - 35.

2. Ibrahim Al Ayed. What Makes Patients Leave Against Medical Advice? J T U Med Sc 2009; 4(1): $16-22$.

3. Saitz R, Ghali WA, Moskowitz MA. The impact of leaving against medical advice on resource utilization. J Gen Inter Med. 2000; 15: 103 - 107.

4. Devitt PJ, Devitt AC, Dewan A. Does identifying a discharge as "against medical advice" confer legal protection? J Fam Pract. 2000; 4: $224-227$.

5. Devitt PJ, Devitt AC, Dewan M. An examination of whether discharging patients against medical advice protects physicians from malpractice charges. Psych Serv. 2000; 51: 899-902.

6. Moyse SH, Osmun WE. Discharge against medical advice: a community hospital experience. Can J Rur 
Med. 2004; 9: 149-153.

7. Anis AH, Sun H, Guh DP, Palepu A, Schechter MT, O'shaughnessy MV. Leaving hospital against medical advice among HIV-positive patients. CMAJ. 2002; 167: 633-637.

8. Jeffer EK. Against Medical Advice: Part I and II. Mil Med 1993; 158 (2): 69-76.

9. Franks P, Meldrum S, Fiscella K. Discharges against medical advice: Are race / ethnicity predictors? J Gen Intern Med. 2006; 21: 955 - 960.

10. SC Nwokediuko, EB Arodiwe. Discharge Against Medical Advice in Enugu, South Eastern Nigeria Some Ethical and Legal Aspects. J Coll Med 2008; 13 (1): 34 - 38 .

11. Ding R, Jung JJ, Kirsch TD, Levy F, McCarthy ML. Uncompleted emergency department care: patients who leave against medical advice. Acad Emerg Med. 2007; 14: 870 - 876 .

12. Ahmed LA, Akinboboye O, Ilesanmi OS, Adeleke O, Olatunde L, Udonwa N. Determinants of Discharge against Medical Advice in a Tertiary Hospital in a Semi-Urban Area of South-Western Nigeria. Int J Car Sci September-December 2015; 8 (3): 519 .

13. Nasir AA, Babalola MO. Clinical spectrum of discharges against medical advice in a developing country. Indian J. Surg. April 2008; 70: 68-72.

14. Akiode O, Musa AA, Shonubi AMO, Salami BA, Oyelekan AAA. Trends of discharges against medical advice in a suburban surgical practice in Nigeria. Trop Doct 2005; 35: 51-52.

15. Aliyu ZY. Discharge against medical advice: sociodemographic, clinical and financial perspectives. Int J Clin Pract 2002; 56: 325-327

16. Bioku MJ, Obalim-Chris A, Igwilo C, Adewumi O, Aremu G, Adamu H, Eziechila C, Aiyekomogbon J. Prospective Evaluation of Cases of Discharge against Medical Advice in Abuja, Nigeria. The Scientific World Journal, Volume 2015, 4 pages, http://dx.doi.org/10.1155/2015/314817, Article ID 314817.

17. Adina E. Feinberg, Martin F. McKneally, Karen M. Devon. What are the physicians obligations when a patient is discharged against medical advice? Royal college of Physicians and Surgeons of Canada publication. Assessed from www.royalcollege.ca/rcsite/bioethics/cases. accessed 27 june 2019.

18. Leaving Against Medical Advice (AMA). (cited November 2018). Available

from:https://www.cmpaacpm.ca/serve/docs/ela/goo dpracticesguide/pages/communication/Informed_Di scharge/leaving_against_medical_advice-e.html

19. Fadare JO, Babatunde OA, Olanrewaju T, Busari O. Discharge against medical advice: Experience from a rural Nigerian hospital. Ann Nig Med 2013; 7: 605.

20. Fadare JO, Jemilohun AC. Discharge against medical advice: Ethico-legal implications from an African perspective. S Afr J BL 2012; 5(2): 98 101. 